\title{
Digital Dilemma 2018: Digital Presentations in Biological Anthropology and Bioarchaeology
}

Cara S. Hirst ${ }^{1}$, Michael B. C. Rivera ${ }^{2}$, Thomas J. Siek ${ }^{* 1}$, Lisa Monetti ${ }^{1}$, Rachael M. Carew $^{3}$ and Suzanna White ${ }^{4}$

How to cite: Hirst et al. 'Digital Dilemma 2018: Digital Presentations in Biological Anthropology and Bioarchaeology'. Papers from the Institute of Archaeology, 2020, 29(1): pp. 1-15.

Published: $17 / 12 / 2020$

\section{Peer Review:}

This article has been peer reviewed through the journal's standard double-blind review.

\section{Copyright:}

(C) 2020, The Author(s). This is an Open Access article distributed under the terms of the Creative Commons Attribution License (CC-BY) 4.0 https://creativecommons.org/licenses/by/4.0/, which permits unrestricted use, distribution and reproduction in any medium, provided the original author and source are credited

\section{Open Access:}

Papers from the Institute of Archaeology is a peer-reviewed open access journal.

\footnotetext{
${ }^{*}$ Correspondence: tjsiek5@gmail.com

${ }^{1}$ Institute of Archaeology, UCL

2 Independent Researcher

${ }^{3}$ Department of Security and Crime Science, UCL; Centre for the Forensic Sciences, UCL

${ }^{4}$ Department of Anthropology, UCL
} 


\title{
Conference Proceedings, Digital Dilemma 2018
}

\section{Digital Dilemma 2018: Digital Presentations in Biological Anthropology and Bioarchaeology}

\author{
Cara S. Hirst, Michael B. C. Rivera, Thomas J. Siek, Lisa Monetti, Rachael M. Carew and \\ Suzanna White
}

\begin{abstract}
In academia, funding for conference attendance is limited, and both students and early-career researchers are therefore only able to attend a limited number of conferences. This means that, typically, researchers need to choose between attending multiple local and, at times, more affordable conferences, or one or two large, expensive, international conferences. Local and less expensive conferences may be research-specific but will have a smaller audience and lower networking potential. In biological anthropology and bioarchaeology, the majority of these larger annual conferences are held in North America and Western Europe where travel and accommodation costs can be very high for those outside of these regions. These costs, in addition to visa restrictions, reduce the diversity of participants at academic conferences, skewing attendance to students and researchers from the host countries. Not only does this disadvantage individuals outside of the typical host-countries, but it also limits the breadth of academic dialogue, with inclusion in academic conferences determined all too often by financial resources rather than academic value. This paper discusses the demographics and lack of diversity at some of these large conferences and the factors that are known to limit international conference travel. It then presents the benefits of digital presentation methods using Digital Dilemma 2018 as a case study for how digital presentation methods can be combined with physical presentations at minimal cost and time. We hope that this will encourage more conferences to offer a digital presentation option in the future.
\end{abstract}

Keywords: Conference attendance, demographics, diversity, digital presentation methods

\section{Introduction}

Students and early career researchers are often highly encouraged by supervisors and employers to attend and participate at academic conferences. This serves to showcase their research, invite constructive critique, seek collaboration with others, and establish professional and social networks within their discipline. However, there are associated costs with academic conferences which all students and early career researchers must contend with. This includes conference registration fees, travel costs, and accommodation prices. Travel and accommodation are often the largest expenses as conferences normally last two to three days and take place in other cities or countries. Some students and earlycareer researchers may have funding schemes available to them to assist in covering some 
conference costs, but these funds are often limited and competitive. In other cases, there are no funding schemes available and the costs of attendance must be personally handled by the individual. As a result, students and early-career researchers face two options: they can either attend multiple small local affordable conferences or attend one or two large international expensive conferences in a year. This decision encompasses much planning, usually starting months in advance, and has an indirect impact on their research and career opportunities. Local affordable conferences will have smaller audiences and lower networking and collaboration potential, and international meetings could be impenetrable due to the associated costs, especially if they are hosted in North America or Western Europe. These costs, in addition to possible restrictive visa requirements reduce the diversity in conference attendance, disadvantage students and early career researchers, and limit academic potential.

To help alleviate the pressures and costs associated with participating in academic conferences, we suggest the implementation of digital presentations and posters. A digital presentation could involve a pre-recorded video, an automated slideshow with a recorded audio component, or a live video stream, and does not require the physical presence of the speaker. A digital poster (or "e-poster") is similar as it does not require the physical presence of the author or a traditional academic poster. Instead, the relevant information is portrayed via two to three slides, which are projected on a loop.

The aim of this paper is to highlight the benefits of including digital presentations in academic conferences, with a focus on biological anthropology and bioarchaeology meetings. We will evaluate past conference demographics and the factors hindering conference attendance, including travel costs, funding and visa restrictions to identify common issues faced by researchers and conference organisers. Subsequently, a discussion on the advantages of including digital presentation formats will be put forward using the Digital Dilemma 2018 conference as an example.

\section{Conference Demographics}

In reviewing biological anthropology and bioarchaeology conferences, it is clear that the majority of large, multi-day conferences are held in the United States, Canada, and Europe, as illustrated in Table 1. While demographic data are not available for all of these conferences, a review of published conference abstracts was conducted which analysed the first author affiliation to determine what proportion of presenters were from the host 
country and host continent (see Table 2). While not necessarily an indication that the first author was in physical attendance at the conference, the majority of the conferences assessed require the first author to register and pay fees for the conference. In the absence of demographic data of the conference attendees, this is the best indicator of geographic diversity currently available.

Results from this review revealed that, as expected, the majority of first authors were affiliated with institutions located in the host country and host continent. The Canadian Association of Physical Anthropologists (CAPA) was found to have the lowest level of geographic diversity with over $82.0 \%$ of presenters affiliated with institutions in Canada for the last three years and over $92.0 \%$ from Canada or the United States. The lowest levels of host country inclusion were reported for the 2018 ESHE meeting (4.9\%), although $79.0 \%$ of first authors affiliations were within the host continent. This increased geographic diversity within the host continent may be related to a number of factors such as: reduced cost of travel and accommodation within the host country/continent; the conference location not being restricted to a single country or continent (such as ESHE and the Paleopathology Association meetings); and bi-annual conferences being more attractive for scholars with finite allocations of funding.

\begin{tabular}{|l|l|}
\hline Location & Organisation \\
\hline USA and Canada & $\begin{array}{l}\text { American Association of Physical Anthropologists (AAPA), Society for American } \\
\text { Archaeology, Paleopathology Association (PPA), American Anthropological Association, } \\
\text { Canadian Association of Physical Anthropologists (CAPA), Canadian Archaeology } \\
\text { Association, Society for Applied Anthropology, Human Biology Association, Dental } \\
\text { Anthropology Association, American Academy of Forensic Scientists (AAFS) }\end{array}$ \\
\hline Europe & $\begin{array}{l}\text { European Society for the study of Human Evolution (ESHE), European Paleopathology } \\
\text { Association (bi-annually), British Association of Biological Anthropologists and } \\
\text { Osteologists, European Association of Archaeologists }\end{array}$ \\
\hline $\begin{array}{l}\text { Other } \\
\text { Association, New Zealand Archaeology Association, Australian Anthropological } \\
\text { Association }\end{array}$ \\
\hline
\end{tabular}

Table 1: Location of conferences in biological anthropology and bioarchaeology, excluding conferences that solely focus on research conducted in the specific regions or countries where they are hosted 


\begin{tabular}{|c|c|c|c|c|c|}
\hline Conference & $\mathbf{n}$ & Host Country & $\begin{array}{l}\text { Proportion of } \\
\text { First Authors }\end{array}$ & $\begin{array}{l}\text { Host } \\
\text { Continent }\end{array}$ & $\begin{array}{l}\text { Proportion of } \\
\text { First Authors }\end{array}$ \\
\hline $\begin{array}{l}\text { AAFS (Anthropology section) } \\
2019\end{array}$ & 141 & USA & $82 \%$ & North America & $86 \%$ \\
\hline $\begin{array}{l}\text { AAFS (Anthropology section) } \\
2018\end{array}$ & 145 & USA & $86 \%$ & North America & $90 \%$ \\
\hline $\begin{array}{l}\text { AAFS (Anthropology section) } \\
2017\end{array}$ & 138 & USA & $73 \%$ & North America & $80 \%$ \\
\hline $\begin{array}{l}\text { AAFS (Anthropology section) } \\
2016\end{array}$ & 130 & USA & $74 \%$ & North America & $75 \%$ \\
\hline AAPA 2019 & 1082 & USA & $78.8 \%$ & North America & $82.8 \%$ \\
\hline AAPA 2018 & 1141 & USA & $78.7 \%$ & North America & $83.1 \%$ \\
\hline AAPA 2017 & 1264 & USA & $73.2 \%$ & North America & $77.7 \%$ \\
\hline AAPA 2016 & 1101 & USA & $81.1 \%$ & North America & $84.2 \%$ \\
\hline BABAO $2017^{1}$ & 130 & UK & $66 \%$ & Europe & $91.5 \%$ \\
\hline BABAO 2016 & 105 & UK & $71.4 \%$ & Europe & $91.4 \%$ \\
\hline CAPA 2018 & 127 & Canada & $82.6 \%$ & North America & $99.2 \%$ \\
\hline CAPA 2017 & 113 & Canada & $83.1 \%$ & North America & $92.0 \%$ \\
\hline CAPA 2016 & \begin{tabular}{|l|}
72 \\
\end{tabular} & Canada & $93.0 \%$ & North America & $95.8 \%$ \\
\hline ESHE 2018 & 205 & Portugal & $4.9 \%$ & Europe & $79.0 \%$ \\
\hline ESHE 2017 & 218 & Netherlands & $5.0 \%$ & Europe & $78.4 \%$ \\
\hline ESHE 2016 & 225 & Spain & $26.7 \%$ & Europe & $84.0 \%$ \\
\hline European PPA 2016 & 88 & Russia & $19.3 \%$ & Europe & $79.5 \%$ \\
\hline North American PPA $2019^{2}$ & 84 & USA & $46.4 \%$ & North America & $53.0 \%$ \\
\hline South American PPA 2017 & 96 & Chile & $18.7 \%$ & South America & $84.3 \%$ \\
\hline
\end{tabular}

Table 2: Proportion of first author presenters from the host country and continent for several major biological anthropology and bioarchaeology conferences. Data from online conference proceedings and published abstracts

In addition to the lack of geographic diversity at these conferences, recent analyses of the memberships of the American Association of Physical Anthropologists (AAPA) and American Anthropological Association (AAA) reported that 87\% of AAPA and 70\% of AAA members identified as White (Antón et al. 2017). While many associations are attempting to encourage diversity and attendance (Villamil 2017, Antón et al. 2017) by offering travel grants, hosting panels and sessions on the importance of inclusion and equity within the disciplines, and reducing conference fees, such methods fail to address

\footnotetext{
1 The abstract and author affiliations for BABAO 2018 are not currently available online

2 Author affiliation and location was not available in the abstract books for the North America PPA 2018 and 2017 meetings
} 
all of the factors limiting international attendance. Although digital presentation methods have been employed in other fields (Neustaedter 2016), the means of presenting digitally are rarely used within biological anthropology and bioarchaeology conferences.

\section{Factors Limiting Conference Attendance}

Before considering the potential benefits of including digital presentations in academic conferences it is first necessary to consider some of the factors which impact international conference attendance and disproportionately influence international attendance.

\section{Travel Costs}

The travel costs associated with attending international conferences are known to be a significant factor in determining conference attendance (Rittichainuwat et al. 2001, Severt et al., 2007, Yoo and Chon 2008, Mair and Thompson 2009, Yoo and Zhao 2010, Superio and Anderson 2016, Mair et al., 2018). While there is little data available regarding the average expenditure for international conference attendance, an informal review of expenditure reports from $\mathrm{PhD}$ students in the United Kingdom revealed that expenses typically ranged between 250-400 GBP for conferences within Europe and 800-1500 GBP for conferences outside Europe. These costs are based on early-bird student registration fees, sharing accommodation, and sourcing cheaper accommodation further from the conference venue. While some conferences do offer reduced-rate accommodation for attendees, these prices are not necessarily affordable on a student budget. For instance, the 2018 AAPA meeting in Austin, Texas, advertised special rate accommodation of 215-289 USD (approximately 170-228 GBP) per night.

The cost of accommodation, therefore, makes sharing rooms in hotels, holiday inns, Airbnb's and hostels the norm, with two-bed rooms frequently shared between four individuals. As a result, several conference organisations such as the AAPA have initiated room share websites where attendees can get in touch with others looking to share accommodation. Web services such as ConferenceShare, which provide a similar service, can be particularly helpful for international attendees. However, sharing accommodation may not a viable option for all and may be particularly difficult for those who are travelling with children or living with disabilities or mental health problems which already make international travel and conference attendance more challenging (England, 2016, Kirkham et al., 2016, Tower and Latimer 2016, Bos et al. 2017, Calisi 2018, Hannam-Swain 2018, Swann 2019, Syma 2019, ). 
Additionally, the prospect of room sharing may be more of a concern to some individuals who may be worried about others intolerance, prejudice, and harassing behaviour towards them, and there are numerous example on online forums and blogs where individuals have expressed their concern about potential room sharing relating to gender, sexual orientation, gender identity, or being pushed to share with advisors/supervisors (such as Anonymous 2012, 2015, 2018b).

\section{Funding}

Funding bodies in the United Kingdom typically provide funding for $\mathrm{PhD}$ students to attend, on average, two international conferences during the three to four years it takes for students to complete their degree (Anonymous 2009, AHRC 2010, Doran 2011, SOAS 2018, Warwick 2018, King's College London 2018, University of Leicester 2018). Although, even when funding is available, the majority of universities and funding bodies only provide compensation funding after the event and as such, researchers need to have sufficient personal funding to cover the initial travel and conference fees (Fullick 2016, Anonymous 2018a, Thomson 2019). The practice of compensation funding in academia has been heavily criticised, especially as compensation funding differentially affects students and early-career researchers, individuals for whom conference attendance and presentations are extremely important for their professional development (Fullick 2016, Flaherty 2017, Sagers 2019, Thomson 2019). Unfortunately, detailed statistics are not available regarding the average expenses incurred and funding received during the course of a $\mathrm{PhD}$ in other countries/regions, or by scholars from institutions outside the North Atlantic nations. This makes it difficult to assess the real costs experienced by all who attend conferences.

\section{Visa Restrictions}

Visa and border restrictions are known to limit attendance at international academic conferences (Neustaedter et al. 2016, Elsahar 2018, Nicolson 2018, Weaver 2018). For instance, in 2016 the African Studies Association UK held a conference at the University of Cambridge where five conference presenters were denied visas. Three were senior academics and two were junior academics who had received scholarship awards to allow them to attend the conference (Nolte and Manji 2017). Similarly, thirteen prospective presenters from Gaza were refused travel permits through Israel and Jordan necessary to attend the Lancet Palestinian Health Alliance conference held in Beirut in 2018 (Nicolson 2018). However, there has been relatively little research into the impact of visa restrictions 
on attendance at academic conferences. Instead, the majority of data come from anecdotal evidence and case studies where individuals were prevented access to the host country. As such, the true impact of visa restrictions on attendance and presentation at academic conferences is unknown. Furthermore, as visa and travel restrictions in the typical host countries (i.e. USA) are likely to get more restrictive (Nicolson 2018, Weaver 2018), such restrictions may act to further limit international conference attendance in the coming years.

\section{Environmental Cost}

More recently, international conference attendance has been heavily criticised for its impact on the environment, particularly the $\mathrm{CO}_{2}$ emissions produced by airline travel. As a result, the environmental cost of academic conferences is having an increasing impact on attendance (Anglaret et al. 2019, Kier-Byfield 2019). While air travel is by no means the only environmentally damaging aspect of academic conferences — with single use plastics, promotional material and other merchandise adding to the environmental cost of conferences - airline travel is by far the largest contributor. Jäckle (2019) for instance reported that the average $\mathrm{CO}_{2}$ emissions per attendee from five European conferences ranged between 0.5-1.3 tons. Suggestions to reduce the environmental cost of academic conferences range from choosing more centrally located conference venues or venues close to airport 'hubs', attending fewer conferences, virtual conferences, promoting low emission transportation, such as trains, and combining smaller conferences together (Jäckle 2019, Levine 2019). Others have even argued against the need for conferences entirely, claiming that 'Today it is possible to publish in record time, and articles are instantly available online' (Anglaret et al. 2019).

As demonstrated, there are multiple barriers to conference attendance. These factors impact both the breadth of research presented at conferences as well as the careers of the attendees, specifically those outside of the typical host countries. This is far from an exhaustive list of factors which influence conference attendance. Among other inherent factors within academia, such as English being the primary language of academic conferences, as well as systemic racism and sexism, there are no 'quick fix' options available. However, with regard to barriers presented above, one low-cost approach to mitigate their impact on conference attendance would be to incorporate digital presentations in all conferences. 


\section{Digital Presentations: A Possible Solution}

Digital presentations are one way to limit the impact of travel costs, funding, and visa restrictions on academic conference attendance. While not conferring the full benefit of physical attendance at conferences in terms of networking and the inability to attend other sessions, digital presentation methods still offer one way to reduce the inequality in conference attendance and increase academic and social diversity in the research presented at these conferences. The inclusion of digital presentations will further ensure that presentations at academic conferences are determined by the quality of research and not the financial or geographic ability to attend. Some academic fields have already embraced digital presentation and even digital conference attendance. In some cases, mobile audiovisual technology has been made available per digital attendee that allows them to both attend presentations and network (Neustaedter et al. 2016). While these methods are expensive, other forms of digital presentation can be achieved with negligible costs. In the case of live or pre-recorded digital presentations, these do not require additional resources not already required by physical presenters, such as audio and visual equipment. Furthermore, there are a number of free host platforms available where digital presentations can be uploaded — such as YouTube and Metacafe for streaming options while online file sharing platforms such as dropbox and google docs can be used for downloading content - access can either be restricted to conference registrants or made open access.

Conference organisers may be concerned that conference attendance, and subsequently registration fees, would be reduced if digital presentation methods are more widely implemented. It is those benefits that can only be gained from physical attendance, such as networking, that arguably make digital presentations less desirable and therefore unlikely to reduce attendance among those who would otherwise be able to physically attend the conference (Asbury 2017). The use of digital presentations would arguably increase overall number of participants, and, combined with making live-streamed sessions available to digital attendees, a reduced digital conference attendance fee could be charged to these additional participants.

\section{Digital Presentations: Digital Dilemma 2018}

Digital Dilemma 2018 was held at the Institute of Archaeology at University College London (UCL) in London, UK. The conference was attended by c.100 academics. The theme of this conference was a discussion of the benefits and potential problems 
presented by the expansion of digital technologies in biological anthropology and bioarchaeology. Therefore, several presentations were given digitally, including both podium and poster presentations. The option to present digitally was made available from the initial call for papers, with prospective presenters being given the option to present either a digital or physical poster, or a podium presentation. It was made clear that digital presentation methods would only be made available to those who could not attend on the day or who were able to justify that the use of digital media would offer benefits that a physical presentation would not. Three digital podium presentations were accepted from authors that were not able to be in the UK at the time of the conference, either due to financial restraints or other research/work/personal commitments, and two digital posters were displayed.

While methods are available to conduct live digital presentations, and such methods have been used previously at conferences, the organisers were concerned about potential technical issues around live streaming presentations (such as the risk of freezing video streams, sub-par audio quality, loss of connection, etc.). Therefore, the digital presentations were submitted as pre-recorded audio-visual files to the conference organisers one week prior to the event. By using the pre-recorded format, it was ensured that the files would play correctly with good audio quality. In the case of Digital Dilemma 2018, the digital presentations were well received and fitted in smoothly with the other physical live presentations. Digital presentations were treated similarity to other physical presentations even to the extent that they received applause at the end of the presentation. The organisers shared the proceedings of the conference through live-tweeting on Twitter, allowing presenters and participants, both present and remote, to share discussion on the presentations. This model could have been further improved by allowing digital presenters the opportunity to participate in the normal question and answer session following their presentation, using either a reliable video call method, or simply using voice calling.

\section{Final Thoughts}

Digital Dilemma 2018 was a free, one-day conference focusing on a single issue within biological anthropology and bioarchaeology, and lacked the scale and momentum provided by the large annual conferences discussed in this paper. As such, it is predicted that the inclusion of digital presentations options at these conferences would likely have a more pronounced effect and a greater impact on potential researchers. While there has been little investigation into diversity at biological anthropology and bioarchaeology 
conferences, it is clear that the majority of large multi-day annual conferences are hosted in the USA, Canada, and Western Europe, and therefore the costs of conference attendance will be disproportionately felt by those outside of these regions. By continuing to limit access to academic conferences, this will disproportionately benefit researchers from these host countries, reducing diversity at conferences and limiting the voices of researchers and individuals outside of these regions. Knowledge production and exchange within anthropology and archaeology also carries deep-rooted colonial baggage. By increasing inclusivity of who gets the opportunity to present work in front of international audiences, we may better highlight projects from research communities that have been historically excluded. Those organising and reviewing conference abstracts for future events should pay closer attention to traditional knowledge and work that does not conform to European epistemologies, perhaps through the creation of digital spaces for intellectual exchange.

It is necessary to stress that the authors do not propose that the inclusion of digital presentations at academic conferences are a solution to problems with diversity, access, and inclusion at these conferences such as those aforementioned. However, other means to improve diversity, access, and inclusion are costly and may take a long time to affect real change, whereas digital presentations provide an option to reduce the impact of these factors while the biological anthropology and bioarchaeology communities work to resolve the underlying issues. Increased research is required by academic organisations in order to understand the diversity among conference attendees and presenters, as well as the factors which limit or prevent conference attendance in order to develop other strategies to increase inclusion and diversity at these conferences.

Finally, the deadline for abstract submission, particularly for some of the larger conferences, is several months in advance of the conference dates. For instance, AAPA typically close their abstract submission approximately six months prior to the scheduled conference. While this is a necessity, particularly for the larger conferences, and confers advantages in regard to organising travel and accommodation, for many academics, particularly students and early career researchers, it may not be possible to confirm attendance at the time of abstract submission. As a result, there is a tendency for individuals to submit abstracts for poster presentations knowing they may not be able to physically attend the conference. Such decisions may be due to financial reasons, potential schedule conflicts including teaching or research commitments, or career uncertainty. 
Furthermore, some conferences require registration fees to be paid prior to abstract submission. In the case of AAPA, this fee can be refunded if the abstract is rejected, however registration fees are not refunded if the applicant is no longer able to physically attend the conference, at which point the payment is considered a 'charitable donation'. The use of digital presentation formats could alleviate this issue, by allowing those who are no longer able to physically present their work to present this digitally and reduce the number of posters presented by absent researchers.

\section{Conclusion}

The increased implementation/incorporation of digital presentation methods at the larger academic conferences is one way in which the disparity in diversity can be addressed. Digital presentations can be adapted in format and medium depending on limitations and requirements of the individual conferences. Importantly, the inclusion of digital presentations is a step that has no significant financial, time, or labour demands that may prevent implementation, and can be easily incorporated into small and large conferences with any costs incurred being greatly outweighed by the benefits.

In our experience, the inclusion of digital presentations into the Digital Dilemma 2018 conference helped to secure valuable speakers and presentations on topics that would otherwise have been absent. As such, it was well-received by the audience and imposed minimal impact on the organisers. The authors wholeheartedly encourage the use of forward-looking presentation formats, such as digital presentations, in future biological anthropology and bioarchaeology meetings as a first step towards addressing some of the limiting factors affecting diversity of conference participants. Finally, it is clear that more research is needed to understand the factors which influence conference attendance and widespread changes are needed in academia to improve the global exchange of research, as well as the equality and accessibility of academic environments. The development of such actions first requires a greater understanding of these barriers and their impact. The inclusion of digital presentations can limit the impact of many of these barriers and has the potential to increase accessibility to those most marginalised in academia, providing them with a platform to be included in discussions for the future of academia.

Competing Interests: The authors were all on the Digital Dilemma 2018 Committee. 


\section{REFERENCES}

Anglaret, X., Wymant, C., Jean, K., 2019. 'Researchers set an example: fly less'. The Conversation. 13 February 2019. Available at: https://theconversation.com/ researchers-set-an-example-fly-less-111046 (Accessed 14 October 2019).

Anonymous. 2007. 'Overseas conference travel', Find a PhD, 1 December. Available at: https://www.postgraduateforum.com/thread-8114/ (Accessed 27 July 2019).

Anonymous. 2009. 'Overseas conferences - when to use available funding (AHRC)', Find a PhD, 23 February. Available at: https://www.findaphd.com/advice/phddiscussion-thread.aspx?thread $=11444$ (Accessed 18 July 2019).

Anonymous. 2012. 'Room sharing at a science conference'. Ask Meta Filter, 25 February. Available at: https://ask.metafilter.com/209092/Room-sharing-at-a-scienceconference (Accessed 27 July 2019).

Anonymous. 2015. 'Rooming with Faculty at Conferences' The Grad Cafe, 18 December. Available at: https://forum.thegradcafe.com/topic/71525-rooming-with-faculty-atconferences/ (Accessed 27 July 2019).

Anonymous. 2018a. 'How am I supposed to go to conferences with a reimbursement system as a poor TA?', Academia Stack Exchange, April. Available at: https://academia.stackexchange.com/questions/108480/how-am-i-supposed-togo-to-conferences-with-a-reimbursement-system-as-a-poor-ta (Accessed 18 July 2019).

Anonymous. 2018b. 'Postgrad workshops/conferences; sharing rooms as a passing trans person', The Workplace, 29 September. Available at: https://workplace.stackexchange.com/questions/122441/postgrad-workshopsconferences-sharing-rooms-as-a-passing-trans-person (Accessed 27 July 2019).

Antón, S., Malhi, R., Fuentes, A., 2017. Race and diversity in U.S. biological anthropology: A decade of AAPA initiatives. American Journal of Physical Anthropology 165, 158-180.

Asbury, E., 2017. The importance of conference attendance in developing research collaborations. Whitireia Nursing and Health 24, 59-62.

Bos, A., Sweet-Chushman, J., Schneider, M., 2017. Family-friendly academic conferences: a missing link to fix the "leaky pipeline"? Politics, Groups and Identities, 1-11. https://doi.org/10.1080/21565503.2017.1403936 
Calisi, R. and a Working Group of Mothers in Science. 2018. Opinion: How to tackle the childcare- conference conundrum. Proceedings of the National Academy of Sciences of the United States of America 115, 2845-2849. https://doi.org/10.1073/pnas.1803153115 (Accessed: 23 July 2019).

Doran, H., 2011. 'Funding Travel During Your PhD'. Available at: https://blog.jobs.ac.uk/phd-student/funding-travel-during-your-phd/ (Accessed: 18 July 2019).

Elsahar, H., 2018. 'Highlighting visa issues in scientific conferences'. Medium, 9 June. Available at: https://medium.com/@hadyelsahar/highlighting-visa-issues-inscientific-conferences-a4a1bab49dee (Accessed: 18 July 2019).

England, M.R., 2016. Being open in academia: A personal narrative of mental illness and disclosure. The Canadian Geographer 60, 226-231. https://doi.org/10.1111/cag.12270.

Flaherty, C., 2017. 'The great conference con?' Inside Higher Ed, 25 July. Available at: https://www.insidehighered.com/news/2017/07/25/article-sparks-new-roundcriticism-costs-associated-academic-conferences (Accessed 18 July 2019).

Fullick, M., 2016. 'It's time to rethink academic conference funding'. University Affairs, 8 January. Available at: https://www.universityaffairs.ca/opinion/speculativediction/its-time-to-re-think-academic-conference-funding/ (Accessed 18 July 2019).

Gay, P., 2017. 'The unacknowledged costs of academic travel'. Medium, 18 July. Available at: https://medium.com/@starstryder/the-unacknowledged-costs-of-academictravel-2ff0c49b0fe6 (Accessed 18 July 2019).

Hannam-Swain, S., 2017. The additional labour of a disabled PhD student. Disability and Society 33, 138-142. Available at: https://doi.org/10.1080/09687599.2017.1375698 (Accessed 14 October 2019).

Jäckle, S., 2019. WE have to change! The carbon footprint of ECPR general conferences and ways to reduce it. European Political Science. Available at: https://doi.org/10.1057/s4130 (Accessed 14 October 2019).

Kier-Byfield, S., 2019. As an academic, should I worry about my conference carbon foot print? The Guardian, 11 June 2019. Available at: https://www.theguardian.com /education/2019/jun/11/as-academics-should-we-worry-about-our-conferencecarbon-footprint (Accessed 14 October 2019).

Kings College London. 2018. Funding opportunities. Available at: https://www.kcl.ac.uk/study/postgraduate/fees-and-funding (Accessed: 18 July 2019). 
Kirkham, R., Webster, M., Chen, K-L., Vines, J., 2016. Using disability law to expand academic freedom for disabled researchers in the United Kingdom. Journal of Historical Sociology 29, 65-91. https://doi.org/10.1111/johs.12121

Levine, C., 2019. Reducing the Carbon Footprint of Academic Travel. Inside Higher ED, April 18 2019. Available at: https://www.insidehighered.com/views/2019/04/18/ 12-scholars-share-ideas-reducing-carbon-emissions-academic-travel-opinion (Accessed 14 October 2019).

Mair, J., Thompson, K., 2009. The UK association conference attendance decisionmaking process. Tourism Management 30, 400-409.

Mustofa, R., Riani, A., Wardani, D., 2018. 'National conference or international conference? Identifying factors that motivate students to publish their research'. International Multidisciplinary Academic Conference. Asian Institute of Technology, Bangcock, Thailand: 83-89.

Neustaedter, C., Venolia, G., Procyon, J., Hawkins,D., 2016. To beam or not to beam: a study of remote telepresence attendance at an academic conference. Proceedings of the 19th ACM Conference on Computer-Supported Cooperative Work \& Social Computing. Available at: https://doi.org/10.1145/2818048.2819922. (Accessed: 18 July 2019).

Ngamson B. Rittichainuwat, J.A. Beck, J. Lalopa. 2001. Understanding motivators, inhibitors and facilitators of association members in attending international conferences. Journal of Convention and Exhibition Management 3, 45-62

Nicolson, D. 2018. 'For some, borders are now an insurmountable barrier to attending international academic conferences'. Impact of Social Sciences Blog, 28 August. Available at: https://blogs.lse.ac.uk/impactofsocialsciences/2018/08/28/forsome-borders-are-now-an-insurmountable-barrier-to-attending-internationalacademic-conferences/ (Accessed: 18 July 2019).

Reed, M., 2017. 'The Cost of Not Traveling'. Inside Higher Ed, 24 July. Available at: https://www.insidehighered.com/blogs/confessions-community-collegedean/cost-not-traveling (Accessed 18 July 2019).

Sagers, J., 2019. 'Reimbursement policies make academia less inclusive'. Science, 14 February. Available at: https://www.sciencemag.org/careers/2019/02/ reimbursement-policies-make- academia-less-inclusive (Accessed: 18 July 2019).

Severt, D., Wang, Y., Chen, P., Breiter, D. 2007. Examining the motivation, perceived performance, and behavioral intentions of convention attendees: Evidence from a regional conference. Tourism Management 28, 399-408. 
SOAS. 2018. Conference Funding. Available at: https://www.soas.ac.uk/doctoralschool /doctoral-school-grants/ (Accessed 18 July 2019).

Superio, D., Anderson, K., 2016. Factors affecting the attendance of IAMSLIC members at IAMSLIC Annual Conference. IAMSLIC Conference Proceedings: 60-71

Swann, N., 2019. Scientist and parent: Are we there yet? eLIFE 8. https://doi.org/10.7554/eLife.49202 (Accessed: 18 July 2019).

Syma, C., 2019. Invisible disabilities: perceptions and barriers to reasonable accommodations in the workplace. Library Management 40, 113-120. https:// doi.org/10.1108/LM-10-2017-0101

Thomson, S., 2019. 'Reimbursement Culture and Widening Participation in Academia'. LSE Impact Blog, 27 March. Available at : https://blogs.lse.ac.uk/impactofsocial sciences /2019/03/27/reimbursement-culture-and-widening-participation-inacademia/ (Accessed: 18 July 2019).

Tower, L., Latimer, M., 2016. Cumulative disadvantage: effects of early career childcare issues on faculty research travel. Affilia 31, 317-330. https://doi.org/10.1177 /0886109915622527 (Accessed: 18 July 2019).

University of Leicester. 2018. Postgraduate research fund 2018/19. Available at: https://www2.le.ac.uk/colleges/ssah/research/postgraduate-research-fund-201819 (Accessed: 18 July 2019).

University of Warwick. 2018. Research students conference funding. Available at: https://warwick.ac.uk/fac/arts/english/currentstudents/postgraduate/pgrhandbo ok/researchstudentsconferencefunding/ (Accessed: 18 July 2019).

Villamil, C., 2017. 'Diversity at the American Association of Physical Anthropologists (AAPA)'. History of Anthropology Newsletter, 29 June. Available at: https://histanthro.org/news/diveristy-at-the-aapa/ (Accessed: 18 July 2019).

Weaver, M., 2018. 'WHO voices alarm as academics denied visas to visit UK conference'. The Guardian, 9 October. Available at: https://www.theguardian.com/uknews/2018/oct/09/who-voices-alarm-academics-denied-visas-to-visit-ukconference (Accessed 18 July 2019).

Yoo, J., Chon, K., 2018. Factors affecting convention participation decision-making: developing a measurement scale. Journal of Travel Research 47, 113-122.

Yoo, J., Zhao, X. 2010 Revisiting determinants of convention participation decisionmaking. Journal of Travel \& Tourism Marketing 27, 179-192. 